Original Report

\title{
A comparison of tracheal scaffold strategies for pediatric transplantation in a rabbit model
}

Elizabeth F Maughan MSc MRCS(ENT) $(1,2)^{*}$, Colin R Butler MRCS $(1,2)^{*}$ Claire Crowley PhD (2), Gui Zhen Teoh PhD (3), Margot Den Hondt PhD (4), Nicholas J Hamilton MRCS (1,5), Robert E Hynds PhD (1), Peggy Lange PhD (6), Tahera Ansari PhD (6), Luca Urbani PhD (2), Samuel M Janes PhD FRCP (1), Paolo De Coppi PhD FRCS (2), Martin A Birchall FRCS (5), Martin J Elliott FRCS (7) ${ }^{\dagger}$

(1) Lungs for Living Research Centre, UCL Respiratory, University College London, London, UK

(2) Stem Cell and Regenerative Medicine Section, Department of Surgery, UCL Institute of Child Health and Great Ormond Street Children's Hospital, London, UK

(3) UCL Centre of Nanotechnology and Regenerative Medicine, Division of Surgery and Interventional Science, University College London, Royal Free London NHS Foundation Trust Hospital, London, UK

(4) Department of Plastic \& Reconstructive Surgery, University Hospitals Leuven, Leuven, Belgium

(5) UCL Ear Institute, The Royal National Throat Nose and Ear Hospital, London, UK

(6) Northwick Park Institute for Medical Research, Northwick Park, London, UK

(7) Department of Thoracic Surgery, Great Ormond Street Hospital NHS Foundation Trust, London, UK

SHORT TITLE: In vivo comparison of tracheal scaffolds

CONFLICT OF INTERESTS: None declared

FUNDING: Grant from GOSH Charities (V1202).

${ }^{*}$ Authors contributed equally.

${ }^{\dagger}$ Author to whom correspondence, reprint requests, and proofs should be sent:

Address: Department of Cardiothoarcic Surgery, Great Ormond Street Hospital, WC1N 3JH

Email: martin.elliott@icloud.com 


\section{ABSTRACT}

Objective

Despite surgical advances, childhood tracheal stenosis is associated with high morbidity and mortality. Various tracheal scaffold strategies have been developed as the basis for bioengineered substitutes, but there is no consensus on which may be superior in vivo. We hypothesized that there would be no difference in morbidity and mortality between three competing scaffold strategies in rabbits.

Study Design

Pilot pre-clinical study.

\section{Methods}

Tracheal scaffolds were prepared by three methods that have been applied clinically and reported: preserved cadaveric ("Herberhold") allografts, detergent-enzymatically decellularized allografts and synthetic scaffolds (nanocomposite polymer POSS-PCU). Scaffolds were implanted into cervical trachea of New Zealand White rabbits ( $n=4$ per group) without cell seeding. Control animals $(n=4)$ received autotransplanted tracheal segments using the same technique. Animals underwent bronchoscopic monitoring of the grafts for 30 days. Macroscopic evaluation of tissue integration, graft stenosis and collapsibility and histological examinations were performed on explants at termination. 
Results

All surgical controls survived to termination without airway compromise. Mild to moderate anastomotic stenosis from granulation tissue was detected, but there was evidence suggestive of vascular reconnection with minimal fibrous encapsulation. In contrast, three of the four animals in Herberhold and POSSPCU groups, and all animals receiving decellularized allografts, required early termination due to respiratory distress. Herberhold grafts showed intense inflammatory reactions, anastomotic stenoses and mucus plugging. Synthetic graft integration and vascularization was poor, whilst decellularized grafts demonstrated malacia and collapse but had features suggestive of vascular connection or revascularization.

\section{Conclusion}

There are mirror-image benefits and drawbacks to non-recellularized, decellularized and synthetic grafts, such that neither emerged as the preferred option. Results from pre-vascularized and/or cell-seeded grafts (as applied clinically) may elucidate clearer advantages of one scaffold type over another.

\section{KEYWORDS}

Tissue Engineering, Tracheal Transplantation, Tracheal Stenosis, Paediatric Airway

\section{LEVEL OF EVIDENCE}

N/A 


\section{INTRODUCTION}

Tracheal stenosis in children can be problematic to treat, particularly longsegment disease where surgical resection is not an option. The increasing use of slide tracheoplasty has transformed the outcomes for children with long-segment congenital tracheal stenosis ${ }^{1}$ but those born with severe congenital malformations of the airway (e.g. type IV laryngeal clefts) or those with extensive large airway disease are often considered untreatable ${ }^{2}$. In such circumstances tracheal replacement is a possible approach ${ }^{3}$.

Allotransplantation has been proposed, but a shortage of donors and the morbidity associated with lifelong post-transplant immunosuppression ${ }^{4}$ are significant hurdles to routine clinical use ${ }^{5-7}$. Cadaveric tracheae (homografts) rendered less immunogenic by chemical processing have been used with patch augmentation and preservation of the existing posterior wall, but clinical outcomes have been mixed and their long-term function is unpredictable. Decellularization of allograft tracheae, where cells (and their epitopes) are removed by mechanical/chemical processing, creates a hypothetically functional and non-allogeneic scaffold ${ }^{8-11}$. Synthetic scaffolds created from novel polymers have also been applied clinically, though the exact material to use in this context remains undecided and outcomes are unclear $^{12}$.

This pilot study directly compares three tracheal replacement strategies using different scaffolds. We hypothesized that there would be no difference in 
morbidity and mortality of rabbits implanted with such tracheal replacements. Scaffolds were not engrafted with cells in this pilot study in order to simplify the comparison of scaffold materials in the absence of other variables such as the influence of seeded cells or growth factors, and to gather data about the in vivo efficacy of acellular scaffolds to inform future experimental groups. Finally, we aim to use observations herein to develop further hypotheses relating to tracheal bioengineering and optimization of a future therapeutic product. 


\section{METHODS}

\section{Animals}

Syngeneic male New Zealand White (NZW) rabbits (weights 2.0-2.5 kg) were used with certified negative status for Pasteurella and other common respiratory pathogens. Rabbits were singly housed with non-particulate bedding and environmental stimulation. Animals were fed a normal hay diet and were pre-operatively assessed for alertness, cardiorespiratory status and weight. Live animal work was ethically approved and carried out under Home Office Project Licence PPL70/7504.

\section{Scaffold Manufacture}

Synthetic tracheae were designed and fabricated using nanocomposite polymer, Polyhedral Oligomeric Silsesquioxane Poly(carbonate-urea) urethane (POSS-PCU), as was used to create a tracheal implant in a single reported patient ${ }^{13}$. Briefly, C-shaped rings of heat-cured POSS-PCU sheets (2 x $2 \times 5 \mathrm{~mm}$ ) were sutured over silicon mandrels, dip-coated with non-porous POSS-PCU and heat-cured to hold them in position. Luminal and external surfaces were coated with porous POSS-PCU (interconnected pore sizes of $40 \mu \mathrm{m}$ and $105 \mu \mathrm{m}$ respectively) to allow for blood vessel ingrowth ${ }^{14}$. Surface layers were water-cured with deionized water and the whole structure was washed for at least 72 hours to ensure complete solvent removal.

Chemically-preserved tracheal homografts were created using the "Herberhold" technique ${ }^{2}$. Rabbit donor tracheae $(n=4)$ were immersed for 14 
days in $4 \%$ formalin in compound sodium lactate solution, before transfer to 4 g/L sodium ethylmercurithiosalicylate (thimerosal) in Dulbecco's phosphatebuffered saline (PBS; Sigma-Aldrich, UK) solution for 56 days. Homografts were stored in acetone until required, with rehydration and thorough washing in sterile saline solution prior to use.

NZW rabbit donor tracheae $(n=4)$ were harvested and underwent decellularization using a detergent-enzyme protocol ${ }^{15,16}$. Following washing in sterile saline, tracheae were incubated in 0.2\% Triton X-100 (Sigma-Aldrich, UK) and $0.2 \%$ Sodium Deoxycholate (Fluka, Switzerland) in PBS, at $37^{\circ} \mathrm{C}$ for 24 hours. After a 48 hour wash in sterile water at $4^{\circ} \mathrm{C}$ (wash water changed three times), tracheae were incubated with $2000 \mathrm{KU}$ (Kunitz Units)/I DNAse (Sigma-Aldrich, UK) and $0.1 \mathrm{~g} / \mathrm{l}$ RNAse (Roche, Switzerland) at $37^{\circ} \mathrm{C}$ for 24 hours to solubilize nuclear contents and degrade DNA. After a further 24 hours of sterile water washing at $4^{\circ} \mathrm{C}$, the DNAse/RNAse step was repeated. Following decellularization, further intensive washing was performed using sterile water over 48 hours. All treatments were carried out under constant agitation. Decellularized scaffolds were sterilized by gamma irradiation (10,000Gy).

\section{Pre-implantation Analysis}

Biomechanical analysis and scanning electron microscopy was performed on batch-matched non-implanted scaffolds from each of the experimental groups and compared to freshly retrieved intact $2 \mathrm{~cm}$ segments of rabbit trachea 
$(n=3)$. Biomechanical properties of composite scaffolds ( $n=4$ in each group) were analysed using a pneumatic Instron Bluehill 5565 tensile tester (Instron Ltd, Bucks, UK) ${ }^{17}$. Tracheal scaffolds ( $n=3$ for each group) were evaluated for tensile strength as a composite structure at longitudinal lengths of $2 \mathrm{~cm}$. Constructs were placed within the jaws of the tensile tester and tension was steadily increased at $100 \mathrm{~mm} / \mathrm{min}$ until rupture of the construct. Stress-strain curves were generated up to the point of rupture and the structure was observed visually to ascertain the location of the tear. Young's (tensile) modulus $\left(\mathrm{YM}_{\mathrm{t}}\right)$, ultimate tensile stress (stress at scaffold failure) and strain at failure were compared to tensile strength recordings. The compressive load sufficient to cause $25 \%$ scaffold occlusion were also measured in anteroposterior $(\mathrm{A}-\mathrm{P})$ and lateral directions on $2 \mathrm{~cm}$ lengths of composite scaffolds. A maximum of $25 \%$ compression was applied as, with its relatively thick wall, the default 50\% compression caused the opposing luminal walls of the POSS-PCU scaffold to come into contact. The stress applied to cause $25 \%$ compression was then used to calculate the Young's (compressive) modulus $\left(\mathrm{YM}_{\mathrm{c}}\right)$. Sections of scaffold materials were analyzed by scanning electron microscopy. Samples were fixed in $2.5 \%$ glutaraldehyde, washed in $0.1 \mathrm{M}$ phosphate buffer, dehydrated in a graded ethanol-water series to $100 \%$ ethanol and critical point dried with carbon dioxide. Samples were sputtercoated with a $2 \mathrm{~nm}$ layer of Gold/Palladium and viewed using a Jeol 7401 FEG scanning electron microscope (Tokyo, Japan).

\section{Surgical Procedure}


Anesthesia of recipient animals $(n=16)$ was induced using intramuscular injections of Xylazine $(6 \mathrm{mg} / \mathrm{kg})$ and Ketamine $(40 \mathrm{mg} / \mathrm{kg})^{18}$ and maintained using 1-3\% Isoflurane in oxygen via mask delivery. Analgesia (Buprenorphine $0.05 \mathrm{mg} / \mathrm{kg}$, intramuscular) and antibiotics (Enrofloxacin $0.9 \mathrm{mg} / \mathrm{kg}$, subcutaneous) were given at induction.

The cervical trachea was exposed from cricoid ring to suprasternal notch and dissected from the esophagus. A $2-2.5 \mathrm{~cm}$ circumferential cervical tracheal segment was excised 4-5 tracheal rings below the cricoid cartilage and washed extracorporeally in sterile PBS containing 1X Penicillin/Streptomycin (Gibco, UK). Controls $(n=4)$ received reversed autologous segments (aimed at reducing the beneficial effect of the mucociliary ladder ${ }^{19}$ ). Experimental groups received $2 \mathrm{~cm}$ lengths of unseeded scaffolds $(\mathrm{n}=4$ each of decellularized, POSS-PCU and Herberhold scaffolds). Anastomoses were performed at proximal and distal graft ends with 6-0 Polydioxanone suture (Supplementary Figure 1). Animals were allowed to recover gradually on discontinuation of Isoflurane delivery.

Post-operative analysis

Close attention was paid post-operatively for signs of graft obstruction or dislodgement, falling oxygen saturations and development of stridor, pain or distress $^{20}$. Analgesia (Buprenorphine $0.05 \mathrm{mg} / \mathrm{kg}$, intramuscular) was given regularly for the first 3 postoperative days. Animals received daily antibiotic administration (Enrofloxacin $0.9 \mathrm{mg} / \mathrm{kg}$, subcutaneous) throughout the study. 
All animals underwent weekly bronchoscopic graft monitoring using a $2.9 \mathrm{~mm}$ $0^{\circ}$ rigid pediatric bronchoscope (Storz, Germany). Anesthesia was induced using the protocol stated above. Developing stenoses were observed and recorded dynamically (iPhone app \& adaptor; endoscope-i, UK), and areas objectively calculated from video stills (ImageJ). No therapeutic bronchoscopic interventions were performed. Animals with asymptomatic stridor were managed conservatively but animals showing signs of respiratory distress (coughing, wheezing, peripheral cyanosis or stridor) underwent immediate termination. At 4 weeks, surviving animals underwent bronchoscopy under terminal anesthesia, followed by autopsy. Transverse sections were taken of the graft (midpoint) and distal native trachea. Longitudinal sections were taken across both proximal and distal anastomoses. Samples were fixed overnight in $4 \%$ paraformaldehyde before paraffin embedding, sectioning and staining.. Slides were digitally scanned (Nanozoomer Digital Pathology, Hamamatsu Photonics, Japan) at 40x magnification for analysis. Epithelialization, granulation tissue formation and neovascularization were evaluated using Hematoxylin and Eosin (H\&E), Masson's Trichrome (MT), Picosirius Red (PR) and Elastin Van Geeson (EVG) stained sections.

\section{Statistical analysis}

Statistical analysis was performed using Prism 6 software (Graphpad, USA). Tensile biomechanical measurements were performed on using the unpaired Student's T-test with Welch's correction for non-equal standard deviations. A- 
P compressive readings were compared using the unpaired Student's T-test with Welch's correction for non-equal standard deviations. Analysis of lateral compressive readings was performed using Wilcoxon matched-pairs signed rank test as native tracheal readings did not follow a normal (Gaussian) distribution. 


\section{RESULTS}

Pre-implantation Biomechanical Assessment

Mean ultimate tensile stress (UTS) was significantly higher for the POSS-PCU scaffold than control trachea ( 3.70 vs $0.55 \mathrm{MPa}, \mathrm{p}=0.0028$ ) but there were no significant differences in UTS between Herberhold, decellularized and control groups. There were no significant differences in maximal tensile strains (MTS) between groups $(p=0.1181)$. Herberhold scaffolds were more brittle than control tracheae, as demonstrated by a lower $\mathrm{YM}_{\mathrm{t}}(1.5 \mathrm{vs} 5.8 \mathrm{MPa}, \mathrm{p}=0.0470)$ but there were no significant differences in $\mathrm{YM}_{t}$ between other groups $(p=0.1292 ;$ Figure 2 and Supplementary Figure 2A-D).

POSS scaffolds required significantly higher loads for $50 \%$ occlusion in both A-P and lateral directions than the other groups $(p<0.0001)$. Herberhold tracheae also showed a significantly increased resistance to $50 \%$ occlusion compared to controls $(p=0.0014(A-P)$ and $p<0.0001$ (lateral)). Decellularized tracheae showed no significant difference compared to controls $(p=0.9859$ (AP) and 0.7699 (lateral)).

Scanning Electron Microscopy

POSS-PCU scaffolds had smooth, highly porous luminal surfaces around smooth casted struts (Supplementary Figure $2 \mathrm{~F} \& \mathrm{~J}$ ), which appeared to 
connect to the underlying porous scaffold (Supplementary Figure 2F). Herberhold sections demonstrated fixed, preserved donor cells and debris both within cartilage lacunae and on surfaces (Supplementary Figure $2 \mathrm{G} \& \mathrm{~K}$ ). Decellularized scaffolds were devoid of cells in both luminal and cartilaginous niches and exhibited preservation of surrounding structures (Supplementary Figure $2 \mathrm{H} \& \mathrm{~L})$.

\section{Mortality and morbidity}

Semi-quantitative bronchoscopic grading of airway stenoses was adapted from the Cotton-Myer Grading System ${ }^{21}$ (Supplementary Table 1). Three trained observers (2 surgeons, 1 material scientist) graded each image independently and were blinded as to group $(\mathrm{EM} / \mathrm{CB} / \mathrm{CC})$. Proximal and distal anastomoses were graded separately and the more severe stenosis recorded as the overall score. Inter-rater reliability was calculated on a random sample of 6 bronchoscopic videos (anastomoses $=10$ ) and found to be $\%$.

All animals survived the first week without respiratory distress or laryngospasm and resumed normal appetite, urination and defecation patterns within 72 hours. Survival (Supplementary Figure 3), post-mortem (Table 1) and bronchoscopic (Table 2) findings diverged significantly from week 2.

Control animals survived to termination with mild to moderate stenoses that stabilized from week 2. Distal anastomotic mucus accumulation was a 
common bronchoscopic finding. At post-mortem, bronchoscopic passage to the carina was possible in three animals; in the fourth animal of the group, circumferential anastomotic granulation prevented scope passage but still allowed for a clear view of a patent tracheal lumen from graft to carina. There were no visible in-graft stenoses, local inflammatory reactions or fibrous encapsulation of grafts.

POSS-PCU and Herberhold groups demonstrated progressive anastomotic stenosis with gradual onset of quiet stridor. In the POSS-PCU group, one rabbit was terminated on development of sudden onset respiratory distress and found to have a mucus plug blocking a severely stenosed distal anastomosis. Two rabbits showed a decline in respiratory reserve over 48 hours and were terminated on day 21. One POSS-PCU rabbit survived to termination with minimal respiratory symptoms, but also demonstrated severe anastomotic stenoses at post-mortem. POSS-PCU grafts were uniformly encapsulated in fibrous tissue with little or no integration into surrounding tissues, with concentric anastomotic stenoses from granulation tissue.

In the Herberhold group, one animal died from laryngospasm following its first bronchoscopy. Two animals developed pneumonia secondary to retained secretions and were terminated on day 19. One animal survived to day 30 with minimal symptoms, but demonstrated severe proximal anastomotic stenosis at post-mortem. Macroscopically, inflammatory exudate was present over the external surface of Herberhold grafts, with intense anastomotic 
granulation tissue. No contact bleeding was evident on the luminal surface of these grafts.

Decellularized grafts showed less severe anastomotic granulation than POSS-PCU or Herberhold grafts. One rabbit was mildly stridulous from day 5 and bilateral vocal cord palsies were observed at first bronchoscopy. Graft malacia (of both anterior and posterior walls) was seen all animals and all required termination due to sudden respiratory distress between days 11 and 20. No obvious pneumonia, mucus plug or secretion accumulation was seen macroscopically at post-mortem. Integration of graft tissue and recipient trachea was macroscopically stronger in the decellularized animals than POSS-PCU and Herberhold groups.

\section{Macroscopic and Histological features}

Control animals displayed mild degrees of anastomotic granulation tissue (Supplementary Figure 4A), and tracheal lumens were patent. No evidence of submucosal fibrosis or fibrous encapsulation of the grafted segment was seen. Pseudostratified, ciliated, columnar epithelium remained intact throughout the length of the reversed autograft (Figure 2A) apart from areas of squamous metaplasia directly over healed anastomoses. Erythrocytes were present within submucosal capillaries in the grafted segments suggesting revascularization or reconnection of submucosal vessels to host vasculature (Supplementary Figure 5A). 
In contrast, fibrous encapsulation of POSS-PCU all grafts were observed with little or no integration into surrounding tissue (Supplementary Figure 4B). There was near-total anastomotic occlusion of tracheal lumens with granulation tissue in all four animals but no ingrowth of tissue into the pores of the biomaterial or vascularization was seen. The inter-connected pores created by the manufacturing method contained frequent basophils, eosinophils and cell debris (Supplementary Figure 5B). No blood vessels or endothelial cells were identified within pores and no elastin deposits were seen within POSS-PCU on Masson's Trichrome or Elastin Van-Gieson staining (data not shown). There were no cells with a respiratory epithelial morphology on luminal surfaces (Figure 2B).

Herberhold grafts all exhibited dense inflammatory infiltrates with deposition of collagen/fibrosis as shown by Masson's Trichrome and PicroSirius Red staining (data not shown). Profuse granulation tissue occluded the lumen at the anastomoses (Supplementary Figure 4C). No blood vessels with lumens containing erythrocytes were observed in sections of the graft (Supplementary Figure 5C). An incomplete, pseudo-stratified epithelium was observed (Figure 2C). Frequent eosinophils were seen throughout the epithelium.

Decellularized grafts showed a large expansion in submucosal layer thickness with stromal cells and a lymphocytic response, although smaller than that seen in POSS-PCU or Herberhold grafts (Supplementary Figure 4D). Unlike other groups, there was some evidence of neovascularization or vascular 
reconnection, as evidenced by small, irregular erythrocyte-filled capillaries in the submucosal layer (Supplementary Figure 5D). There was no evidence of any development of pseudostratified epithelium at 20 days (the longest recorded survival in this group; Figure 2D).

\section{DISCUSSION}

The most effective material for potential use in bioengineered tracheal replacement remains unclear ${ }^{22-24}$. Tracheal interventions are often complicated by granulations and stenosis, regardless of the material chosen for tracheal reconstruction ${ }^{25-28}$. Tracheal 'Herberhold' homografts have been used with moderate success in the clinical setting but do not represent the ideal graft due to limited availability, difficulty in procurement and the requirement for significant and prolonged post-operative airway intervention. These grafts have been principally used for patch augmentation but also to replace sections of airway ${ }^{29}$. A variety of new scaffold materials have emerged as potential candidates but to our knowledge they have not been directly compared. This study tested two alternate technologies against the "standards" of Herberhold homografts and surgical controls in an animal setting that could be considered a relevant model for pediatric airway transplantation.

Rabbits have comparable anatomy and airway dimensions to human neonates and infants ${ }^{30}$ and are widely accepted as an experimental model for tracheal stenosis ${ }^{30,31}$ and transplantation ${ }^{32-34}$. In this pilot study, all surgical 
control animals tolerated a long-segment autograft replacement without any airway compromise or distress. Bronchoscopic follow-up demonstrated little anastomotic granulation or stenosis and grafts at post mortem appeared to retain a ciliated epithelium ${ }^{35}$. This is a significant observation given that the "control" operation completely disconnects the implanted segment of trachea from its vascular supply. This rapid reestablishment of a vascular supply is likely to support integration ${ }^{35-37}$ and attenuate granulation formation. However, the fact that control autografts were not denuded of epithelium may make them a less relevant comparator to unseeded experimental arms ${ }^{30}$.

Animals in POSS-PCU and Herberhold groups inexorably developed occlusive anastomotic granulations and stenosis. The mechanisms that cause this anastomotic stenosis may be different in each group. POSS-PCU grafts were externally encased in a dense fibrous capsule, and the graft easily peeled away at anastomoses from the native tracheal ends implying a lack of tissue integration. The inter-connected pores created by the manufacturing method contained cell debris but no evidence of neovascularization. Inflammatory infiltrates were seen within the submucosal and adventitial layers of Herberhold grafts. An epithelial layer was seen, but this likely represented the remnants of the chemically fixed donor rather than a living, functional neo-epithelium. We hypothesize that the widespread presence of eosinophils represents an acute cell-mediated reaction to the fixed, but still potentially immunogenic, if not allogeneic, material found in these grafts ${ }^{38,39}$. Both POSS-PCU and Herberhold grafts were significantly 'stiffer' than native 
trachea on compression testing. It has been proposed than mechanical mismatch between graft and native tissues can be a negative prognostic indicator for graft integration ${ }^{40}$ and may also contribute to granulation tissue formation at the anastomosis. There was no significant difference in maximal tensile strains between experimental groups and controls, which would indicate a low potential risk of scaffold rupture in therapeutic interventions such as endoluminal ballooning of granulations ${ }^{41}$, at least in the early phase before remodeling. We did not have the facility or equipment capability to manage stenosis and granulations endoscopically during this pilot study, but addition of these capabilities will enable us to more closely model the clinical scenario in future experimental groups, facilitating rabbit survival and enabling evaluation of graft integration over longer periods ${ }^{42}$.

In contrast, decellularized grafts became overtly malacic by the second week post-implantation, implying a degree of remodeling in vivo. Some animals in this group exhibited sudden deteriorations in respiratory function akin to 'dying spells', a clinical hallmark of severe pediatric tracheobronchomalacia ${ }^{43}$. The mechanisms underlying the cellular response to decellularized scaffolds are less clear but may represent a reaction to epitopes or growth factors retained in the scaffold, retained decellularization agent contamination or a remodeling process of the exposed extracellular matrix. Less aggressive tracheal decellularization methods, such as cryopreservation with epithelium denudation ${ }^{44}$, might better preserve graft structure and function but this may be at the expense of increasing immunogenicity, something that will need to 
be assessed experimentally. The contribution of gamma irradiation sterilization to the malacia of tracheal grafts is unknown. Gamma irradiation has been shown to increase resistance and elastance in decellularised mouse lung, albeit at much higher doses than those employed in this study ${ }^{45}$. Temporary intraluminal stenting of decellularized scaffolds might address the problem of malacia during remodeling ${ }^{46}$.

Stenosis may be exacerbated by poor graft neovascularization which could be in part due to the lack of cues to encourage ingrowth ${ }^{47}$ and seeding scaffolds with cells may lead to significant advantages in this regard as well as in functional epithelium establishment ${ }^{30}$. Indeed, the addition of autologous mesenchymal stem cells to decellularized scaffolds has been shown in a pilot study of a similar rabbit model to alter the host response and improve outcomes in terms of regeneration and function ${ }^{33}$. Further experimental arms are planned to test combinations of epithelial and/or mesenchymal stem cell graft seeding ${ }^{48}$ to evaluate the fate of these transplanted cells, their effect on graft granulation and stenosis and their potential contribution towards tracheal regeneration.

\section{CONCLUSION}

Significant developments have been made in the field of conventional transplantation but for allogeneic tracheal transplants appropriately sized donors are scarce and anti-rejection drugs are potentially harmful. In this pilot study we examined multiple scaffold materials that have been employed 
clinically. Although in a small number of animals, neither decellularized nor synthetic scaffolds emerged as a preferred option over 'gold standard' chemically preserved tracheal homografts. Further work is required to identify whether either strategy shows further clinical promise. Work to optimize the integration, vascularization and epithelialization of the candidate(s) should be performed. Experiments with cell-seeded grafts will be essential and will better mimic the use of such scaffolds in compassionate clinical cases than the simplified approach taken here. These may elucidate a clearer advantage of one scaffold material over another in the search for a universally effective means of tracheal replacement in children and adults.

\section{ACKNOWLEDGMENTS}

Live animal work was ethically approved and carried out at the Royal Free Hospital Biological Sciences Unit under Home Office Project License PPL70/7504. The authors would like to thank Mr. Duncan Moore and Mr. Mark Neal for their assistance there. 


\section{FIGURE LEGENDS}

Figure 1: Biomechanical preimplantation analysis of grafts: comparisons of ultimate tensile strain (A) and anterior-posterior compressive load at $50 \%$ occlusion (B).

Figure 2: Haematoxylin \& Eosin (H\&E) staining of luminal surface at midpoint of graft. Scale bar $=100 \mu \mathrm{m}$. (A) Control - largely intact layer of pseudostratified respiratory epithelium. (B) POSS-PCU - No respiratory epithelium seen, eosinophil migration throughout graft (arrow). (C) Herberhold - fixed donor epithelium seen with copious lymphocytic infiltrate. (D) Decellularized grafts - Fibroblastic expansion of luminal surface without respiratory epithelium.

Table 1: Summary of bronchoscopic findings.

Table 2: Representative bronchoscopic findings.

\section{SUPPLEMENTARY FIGURE LEGENDS}

Supplementary Figure 1: Representative intraoperative photographs of endto-end anastomosis of (A) control, (B) POSS-PCU, (C) Herberhold and (D) Decellularized grafts. 
Supplementary Figure 2: Pre-implantation analysis of grafts. Biomechanical testing: comparisons of ultimate tensile stress (A); ultimate tensile strain (B); anterior-posterior (C) and lateral (D) compressive load at $50 \%$ occlusion. Scanning electron microscopy of scaffolds: Transverse sections $x 200$ magnification: (E) Control rabbit trachea; (F) POSS-PCU scaffold; (G) Herberhold and $(H)$ Decellularized grafts. Luminal surfaces x 1000 magnification: (I) Control rabbit trachea; (J) POSS-PCU scaffold; (K) Herberhold and (L) Decellularized grafts.

Supplementary Figure 3: Kaplan-Meier survival curves to experiment termination at four weeks.

Supplementary Figure 4: Haematoxylin \& Eosin (H\&E) staining of longitudinal sections through anastomoses. Scale bar $=500 \mu \mathrm{m}$. (A) Control minimal anastomotic granulation (*). (B) POSS-PCU - lack of scaffold (S) integration with intense overgrowth of granulation tissue $\left({ }^{*}\right) .(\mathrm{C})$ Herberhold intense anastomotic granulation tissue $(G)$ with lymphocytic infiltrate (\#) throughout graft. (D) Decellularized grafts - large submucosal expansion with stromal cells and mucus-filled lumen (M).

Supplementary Figure 5: Haematoxylin \& Eosin (H\&E) staining of submucosal layer at mid-point of graft. Scale bar $500 \mu \mathrm{m}$. (A) Control - intact submucosal vasculature. 
(B) POSS-PCU - pores containing copious cell debris but no discernable

vessels. (C) Herberhold - intact submucosal vasculature with red blood cells

within lumen. (D) Decellularized grafts - copious granulation tissue and

irregular neovascularization with expansion of submucosal layer, suggesting

in-stent stenosis.

\section{Supplementary Table 1: Adaptation of the Cotton-Myer grading system for}

subglottic stenosis.

\section{REFERENCES}

1. Butler CR, Speggiorin S, Rijnberg FM, et al. Outcomes of slide tracheoplasty in 101 children: a 17-year single-center experience. J Thorac Cardiovasc Surg. 2014;147(6):1783-1789.

2. Jacobs JP, Elliott MJ, Haw MP, Bailey CM, Herberhold C. Pediatric tracheal homograft reconstruction: a novel approach to complex tracheal stenoses in children. The Journal of thoracic and cardiovascular surgery. 1996;112(6):1549-1560.

3. Maughan E, Lesage F, Butler CR, Hynds RE, Hewitt R, Janes SM, et al., editors. Airway tissue engineering for congenital laryngotracheal disease. Seminars in Pediatric Surgery; 2016: Elsevier.

4. Kirkman RL, Strom TB, Weir MR, Tilney NL. Late Mortality and Morbidity in Recipients of Long-term Renal Allografts. Transplantation. 1982;34(6):347-351.

5. Kucera KA, Doss AE, Dunn SS, Clemson LA, Zwischenberger JB. Tracheal replacements: part 1. ASAIO Journal. 2007;53(4):497-505.

6. Benden C, Dipchand AI, Danziger-Isakov LA, et al. Pediatric Transplantation: Ten years on. Pediatric Transplantation. 2009;13(3):272-277.

7. Lutolf M, Hubbell J. Synthetic biomaterials as instructive extracellular microenvironments for morphogenesis in tissue engineering. Nature biotechnology. 2005;23(1):47-55.

8. Badylak SF, Gilbert TW. Immune response to biologic scaffold materials. Paper presented at: Seminars in immunology2008.

9. Saxena AK. Tissue engineering: Present concepts and strategies. Journal of Indian Association of Pediatric Surgeons. 2005;10(1):14.

10. Fuchs JR, Nasseri BA, Vacanti JP. Tissue engineering: a 21st century solution to surgical reconstruction. The Annals of thoracic surgery. 2001;72(2):577-591.

11. Ott LM, Weatherly RA, Detamore MS. Overview of tracheal tissue engineering: clinical need drives the laboratory approach. Annals of biomedical engineering. 2011;39(8):2091-2113.

12. Badylak SF, Freytes DO, Gilbert TW. Extracellular matrix as a biological scaffold material: structure and function. Acta biomaterialia. 2009;5(1):1-13.

13. Jungebluth P, Alici E, Baiguera S, et al. Tracheobronchial transplantation with a stem-cellseeded bioartificial nanocomposite: a proof-of-concept study. Lancet. 2011;378(9808):19972004.

14. Chiu Y-C, Cheng M-H, Engel H, et al. The role of pore size on vascularization and tissue remodeling in PEG hydrogels. Biomaterials. 2011;32(26):6045-6051. 
15. Elliott MJ, De Coppi P, Speggiorin S, et al. Stem-cell-based, tissue engineered tracheal replacement in a child: a 2-year follow-up study. Lancet. 2012;380(9846):994-1000.

16. Lange P, Greco K, Partington L, et al. Pilot study of a novel vacuum-assisted method for decellularization of tracheae for clinical tissue engineering applications. Journal of tissue engineering and regenerative medicine. 2015.

17. Partington L, Mordan N, Mason C, et al. Biochemical changes caused by decellularization may compromise mechanical integrity of tracheal scaffolds. Acta biomaterialia. 2012.

18. Delaere PR, Liu ZY, Hermans R, Sciot R, Feenstra L. Experimental tracheal allograft revascularization and transplantation. The Journal of Thoracic and Cardiovascular Surgery. 1995;110(3):728-737.

19. Delaere PR, Liu Z, Delanghe G, Gyselen K, Jorissen M, Feenstra L. Mucociliary clearance following segmental tracheal reversal. The Laryngoscope. 1996;106(4):450-456.

20. Flecknell PA, Liles JH. Assessment of the analgesic action of opioid agonist-antagonists in the rabbit. Veterinary Anaesthesia and Analgesia. 1990;17(1):24-29.

21. Myer CM, O'Connor DM, Cotton RT. Proposed grading system for subglottic stenosis based on endotracheal tube sizes. Annals of Otology, Rhinology \& Laryngology. 1994;103(4):319323.

22. Delaere P, Vranckx J, Meulemans J, et al. Learning curve in tracheal allotransplantation. American Journal of Transplantation. 2012;12(9):2538-2545.

23. Birchall M, Macchiarini P. Airway Transplantation: A Debate Worth Having? Transplantation. 2008;85(8):1075-1080 1010.1097/TP.1070b1013e31816a31810e31814.

24. Rich JT, Gullane PJ. Current concepts in tracheal reconstruction. Current opinion in otolaryngology \& head and neck surgery. 2012;20(4):246-253.

25. Kojima K, Bonassar LJ, Roy AK, Vacanti CA, Cortiella J. Autologous tissue-engineered trachea with sheep nasal chondrocytes. The Journal of thoracic and cardiovascular surgery.2002;123(6):1177-1184.

26. Weidenbecher M, Tucker HM, Gilpin DA, Dennis JE. Tissue-engineered trachea for airway reconstruction. The Laryngoscope. 2009;119(11):2118-2123.

27. Tsugawa C, Nishijima E, Muraji T, et al. Tracheoplasty for long segment congenital tracheal stenosis: analysis of 29 patients over two decades. Journal of pediatric surgery. 2003;38(12):1703-1706.

28. Elliott M, Roebuck D, Noctor C, et al. The management of congenital tracheal stenosis. Paper presented at: International Congress Series2003.

29. Jacobs JP, Quintessenza JA, Andrews T, Burke RP, Spektor Z, Delius RE, et al. Tracheal allograft reconstruction: the total North American and worldwide pediatric experiences. The Annals of thoracic surgery. 1999;68(3):1043-51.

30. Nakagishi Y, Morimoto Y, Fujita M, Ozeki Y, Maehara T, Kikuchi M. Rabbit model of airway stenosis induced by scraping of the tracheal mucosa. The Laryngoscope. 2005;115(6):1087-92.

31. Steehler MK, Hesham HN, Wycherly BJ, Burke KM, Malekzadeh S. Induction of tracheal stenosis in a rabbit model-endoscopic versus open technique. The Laryngoscope. 2011;121(3):509-14.

32. Delaere PR, Liu ZY, Hermans R, Sciot R, Feenstra L. Experimental tracheal allograft revascularization and transplantation. The Journal of Thoracic and Cardiovascular Surgery. 1995;110(3):728-37.

33. Batioglu-Karaaltin A, Karaaltin MV, Ovali E, Yigit O, Kongur M, Inan O, et al. In Vivo Tissue-Engineered Allogenic Trachea Transplantation in Rabbits: A Preliminary Report. Stem Cell Reviews and Reports. 2015;11(2):347-56.

34. Den Hondt M, Vanaudenaerde BM, Delaere P, Vranckx JJ. Twenty years of experience with the rabbit model, a versatile model for tracheal transplantation research. Plastic and Aesthetic Research. 2016;3(7):223-30.

35. Zagalo C, Grande NR, dos Santos JM, Monteiro E, Brito J, Aguas AP. Tracheal transplantation: Cytological changes studied by scanning and transmission electron microscopy in the rabbit. Laryngoscope. 2001;111(4):657-662.

36. Luo X, Liu Y, Zhang Z, et al. Long-term functional reconstruction of segmental tracheal defect by pedicled tissue-engineered trachea in rabbits. Biomaterials. 2013;34(13):3336-3344.

37. Delaere PR, Hermans R. Tracheal autotransplantation as a new and reliable technique for the functional treatment of advanced laryngeal cancer. The Laryngoscope. 2003;113(7):12441251 . 
38. Chua M, Chui CK, Rai B, Lau D. Development of a patient specific artificial tracheal prosthesis: Design, mechanical behavior analysis and manufacturing. Paper presented at: Engineering in Medicine and Biology Society (EMBC), 2013 35th Annual International Conference of the IEEE2013.

39. Genden EM, Iskander AJ, Bromberg JS, Mayer L. Orthotopic tracheal allografts undergo reepithelialization with recipient-derived epithelium. Archives of Otolaryngology-Head \& Neck Surgery. 2003;129(1):118-123.

40. Asawa Y, Sakamoto T, Komura M, et al. Early stage foreign body reaction against biodegradable polymer scaffolds affects tissue regeneration during the autologous transplantation of tissue-engineered cartilage in the canine model. Cell transplantation. 2012;21(7):1431-1442.

41. Visaya JM, Ward RF, Modi VK. Feasibility and mortality of airway balloon dilation in a live rabbit model. JAMA Otolaryngology-Head \& Neck Surgery. 2014;140(3):215-219.

42. Nouraei SAR, Singh A, Patel A, Ferguson C, Howard DJ, Sandhu GS. Early endoscopic treatment of acute inflammatory airway lesions improves the outcome of postintubation airway stenosis. The Laryngoscope. 2006;116(8):1417-1421.

43. Tan JZY, Ditchfield M, Freezer N. Tracheobronchomalacia in children: review of diagnosis and definition. Pediatric radiology. 2012;42(8):906-915.

44. Ito Y, Suzuki H, Hattori Y, et al. Complete replacement of tracheal epithelia by the host promotes spontaneous acceptance of orthotopic tracheal allografts in rats. Paper presented at: Transplantation proceedings2004.

45. Uriarte JJ, Nonaka PN, Campillo, N et al. Mechanical properties of acellular mouse lungs after sterilization by gamma irradiation. Journal of the mechanical behavior of biomedical materials. 2014;40: 168-177.

46. Hysi I, Wurtz A, Zawadzki C, et al. Immune tolerance of epithelium-denuded-cryopreserved tracheal allograft. European Journal of Cardio-Thoracic Surgery. 2014;45(6):e180-e186.

47. Walles T, Giere B, Hofmann M, et al. Experimental generation of a tissue-engineered functional and vascularized trachea. The Journal of thoracic and cardiovascular surgery. 2004;128(6):900-906.

48. Lee DY, Lee JH, Ahn H-J, et al. Synergistic effect of laminin and mesenchymal stem cells on tracheal mucosal regeneration. Biomaterials. 2015;44(0):134-142. 
A

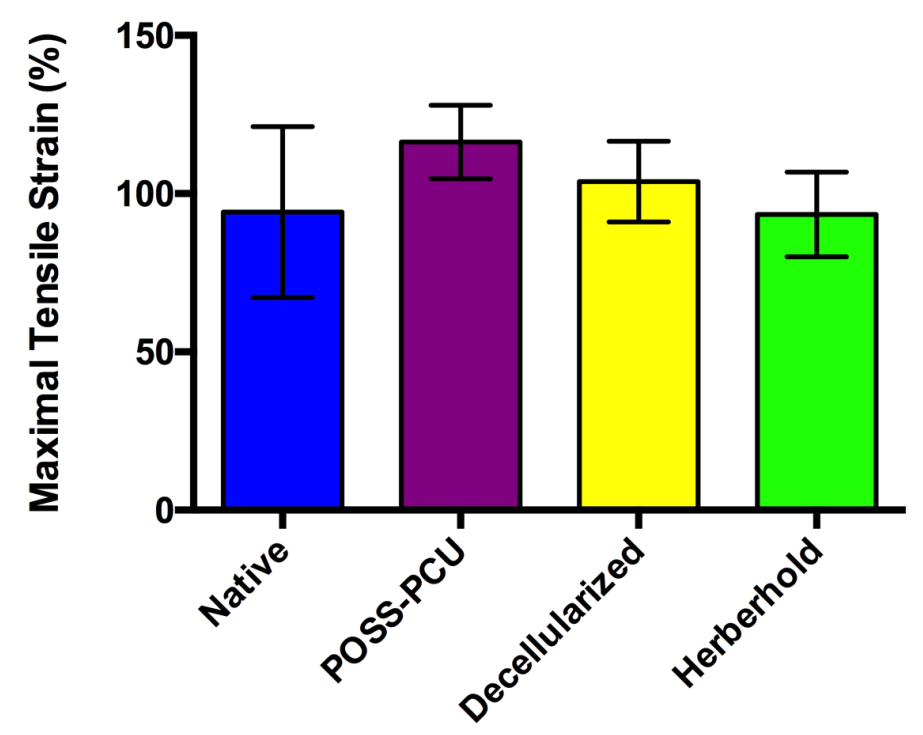

B

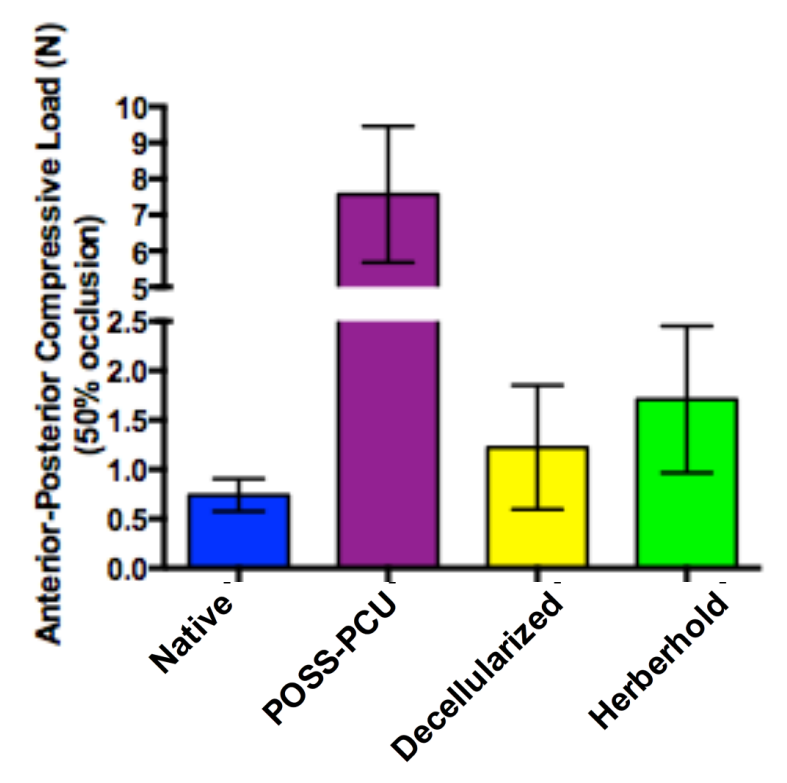

Figure 1: Biomechanical preimplantation analysis of grafts: comparisons of ultimate tensile strain (A) and anterior-posterior compressive load at 50\% occlusion (B). 
Table 1: Summary of bronchoscopic findings. Grading refers to degree of anastomotic stenosis (see Supplementary Table 1)

\begin{tabular}{|c|c|c|c|c|c|}
\hline Animal & Week 1 & Week 2 & Week 3 & Week 4 (Terminal) & $\begin{array}{l}\text { Survival in Days } \\
\text { (Cause of Death) }\end{array}$ \\
\hline \multicolumn{6}{|c|}{ Control (Autograft) } \\
\hline 1 & - Grade 0 (both ends) & $\begin{array}{l}- \text { - Grade } 0 \text { (proximal) } \\
\text { - Grade I (distal) - granulation tissue at posterior } \\
\text { distal suture line } \\
\text { - Contact bleeding }\end{array}$ & $\begin{array}{l}\text { - Grade } 0 \text { (proximal) } \\
\text { - Grade II (distal) - progression of exophytic } \\
\text { granulation tissue }\end{array}$ & $\begin{array}{l}\text { - Grade II (distal) - focal granulation tissue as } \\
\text { before }\end{array}$ & $\begin{array}{l}32 \\
\text { (End of experiment) }\end{array}$ \\
\hline 2 & - Grade 0 (both ends) & $\begin{array}{l}\text { - Grade } 0 \text { (both ends) } \\
\text { - Mucus overlying distal anastomosis (easily cleared) }\end{array}$ & - Grade I (both ends) & $\begin{array}{l}\text { - Grade I (both ends) - able to pass scope to } \\
\text { carina }\end{array}$ & $\begin{array}{l}32 \\
\text { (End of experiment) }\end{array}$ \\
\hline 3 & - Grade 0 (both ends) & $\begin{array}{l}\text { - Grade I (proximal) } \\
- \text { Grade } 0 \text { (distal) } \\
\text { - Mucus overlying anastomoses distal > proximal }\end{array}$ & - Grade 0 (distal) & - Grade 0 (distal) & $\begin{array}{l}30 \\
\text { (End of experiment) }\end{array}$ \\
\hline 4 & - Grade 0 (both ends) & - Grade 0 (both ends) & - Grade I (both ends) & - Grade I (both ends) & $\begin{array}{l}30 \\
\text { (End of experiment) }\end{array}$ \\
\hline \multicolumn{6}{|c|}{ POSS-PCU (Synthetic Nanocomposite Polymer Graft) } \\
\hline 5 & - Grade 0 (distal) & $\begin{array}{l}\text { - Grade I (proximal) - eccentric stenosis posterior > } \\
\text { anterior } \\
\text { - Grade } 0 \text { (distal) }\end{array}$ & - Grade IV (distal) - 'pinhole' stenosis & - Loose secretions. & $\begin{array}{l}30 \\
\text { (End of experiment) }\end{array}$ \\
\hline 6 & - Grade 0 (both ends) & - Grade I (distal) - just able to pass scope & $\begin{array}{l}\text { - Grade II (proximal) } \\
\text { - Grade IV (distal) - 'pinhole' stenosis }\end{array}$ & & $\begin{array}{l}21 \\
\text { (Termination - anastomotic stenosis) }\end{array}$ \\
\hline 7 & - Grade 0 (both ends) & $\begin{array}{l}\text { Procedure abandoned (anaesthesia induction } \\
\text { failure \& mild laryngospasm on trial of gas } \\
\text { anaesthetic) }\end{array}$ & - Grade IV (distal) 'pinhole' & & $\begin{array}{l}21 \\
\text { (Termination - anastomotic stenosis) }\end{array}$ \\
\hline 8 & - Grade I (distal) - contact bleeding & - Copious loose secretions & - Mucus obliterating central graft lumen & & $\begin{array}{l}19 \\
\text { (Mucus plugging on background of stenosis) }\end{array}$ \\
\hline \multicolumn{6}{|c|}{ Herberhold (Preserved Rabbit Trachea) } \\
\hline 9 & - Grade 0 (both ends) & $\begin{array}{l}\text { - Grade I (proximal) } \\
\text { - Grade } 0 \text { (distal) }\end{array}$ & - Grade II (both ends) & $\begin{array}{l}\text { - Grade IV (proximal) } \\
\text { - Grade II (distal) }\end{array}$ & $\begin{array}{l}30 \\
\text { (End of experiment) }\end{array}$ \\
\hline 10 & - Grade 0 (both ends) & $\begin{array}{l}\text { - Grade } 0 \text { (proximal) } \\
\text { - Grade III (distal) }\end{array}$ & $\begin{array}{l}\text { - Grade II (proximal)* } \\
\text { - Grade III (distal) }\end{array}$ & & $\begin{array}{l}19 \\
\text { (Termination - pneumonia from retained } \\
\text { secretions) }\end{array}$ \\
\hline 11 & - Grade 0 (both ends) & - Grade II (both ends) & $\begin{array}{l}\text { - Grade III (proximal)* } \\
\text { - Grade II (distal) }\end{array}$ & & $\begin{array}{l}\text { (Termination - pneumonia from retained } \\
\text { secretions) }\end{array}$ \\
\hline 12 & - Grade 0 (both ends) & - & & & $\begin{array}{l}7 \\
\text { (Laryngospasm on anaesthesia reversal) }\end{array}$ \\
\hline \multicolumn{6}{|c|}{ Decellularized Rabbit Trachea } \\
\hline 13 & $\begin{array}{l}\text { - Grade } 0 \text { (both ends) } \\
\text { - In-drawing of trachealis into graft } \\
\text { lumen }\end{array}$ & \begin{tabular}{|l|} 
- Grade II (proximal) \\
- Grade I (idstal) \\
- In-drawing of trachealis into graft lumen
\end{tabular} & & & 20 (Mucus plugging on background of malacia) \\
\hline 14 & $\begin{array}{l}\text { - Bilateral vocal cord palsies } \\
\text { - Grade 0 (both ends) }\end{array}$ & $\begin{array}{l}\text { - Bilateral vocal cord palsies - Grade } 0 \text { (proximal) } \\
\text { - Grade I (distal) } \\
\text { - Signifificant graft malacia }\end{array}$ & & & $\begin{array}{l}16 \text { (Termination - respiratory distress from } \\
\text { malacia on background of VC palsies) }\end{array}$ \\
\hline 15 & $\begin{array}{l}\text { - Grade } 0 \text { (both ends) } \\
\text { - In-drawing of trachealis into graft } \\
\text { lumen }\end{array}$ & $\begin{array}{l}\text { - Grade } 0 \text { (both ends) } \\
\text { - Severe graft malacia* (collapse of both anterior and } \\
\text { posterior graft walls into lumen on inspiration) }\end{array}$ & & & $\begin{array}{l}15 \text { (Termination - respiratory distress from } \\
\text { malacia) }\end{array}$ \\
\hline 16 & $\begin{array}{l}\text { - Grade } 0 \text { (both ends) } \\
\text { - In-drawing of trachealis into graft } \\
\text { lumen }\end{array}$ & & & & $\begin{array}{l}11 \text { (Termination - respiratory distress from } \\
\text { malacia) }\end{array}$ \\
\hline
\end{tabular}


Table 2: Representative bronchoscopic findings

\begin{tabular}{|c|c|c|c|c|}
\hline & Control & POSS-PCU & Herberhold & Decellularized \\
\hline \multicolumn{5}{|l|}{ Week 2} \\
\hline Summary of Findings & $\begin{array}{l}\text { Both anastomoses patent with } \\
\text { minimal ridging of suture lines }\end{array}$ & $\begin{array}{l}\text { Widely patent proximal } \\
\text { anastomosis with mucus } \\
\text { overlying the distal suture line }\end{array}$ & $\begin{array}{l}\text { Passable developing } \\
\text { anastomotic stenosis }\end{array}$ & $\begin{array}{l}\text { Malacia (heterogeneous } \\
\text { severity) }\end{array}$ \\
\hline \multicolumn{5}{|l|}{ Week 4} \\
\hline Summary of Findings & $\begin{array}{l}\text { Minimal progression of stenosis } \\
\text { at either anastomosis }\end{array}$ & $\begin{array}{l}\text { Severe anastomotic stenosis } \\
\text { from granulation tissue }\end{array}$ & $\begin{array}{l}\text { Severe anastomotic stenosis } \\
\text { from granulation tissue }\end{array}$ & N/A \\
\hline
\end{tabular}



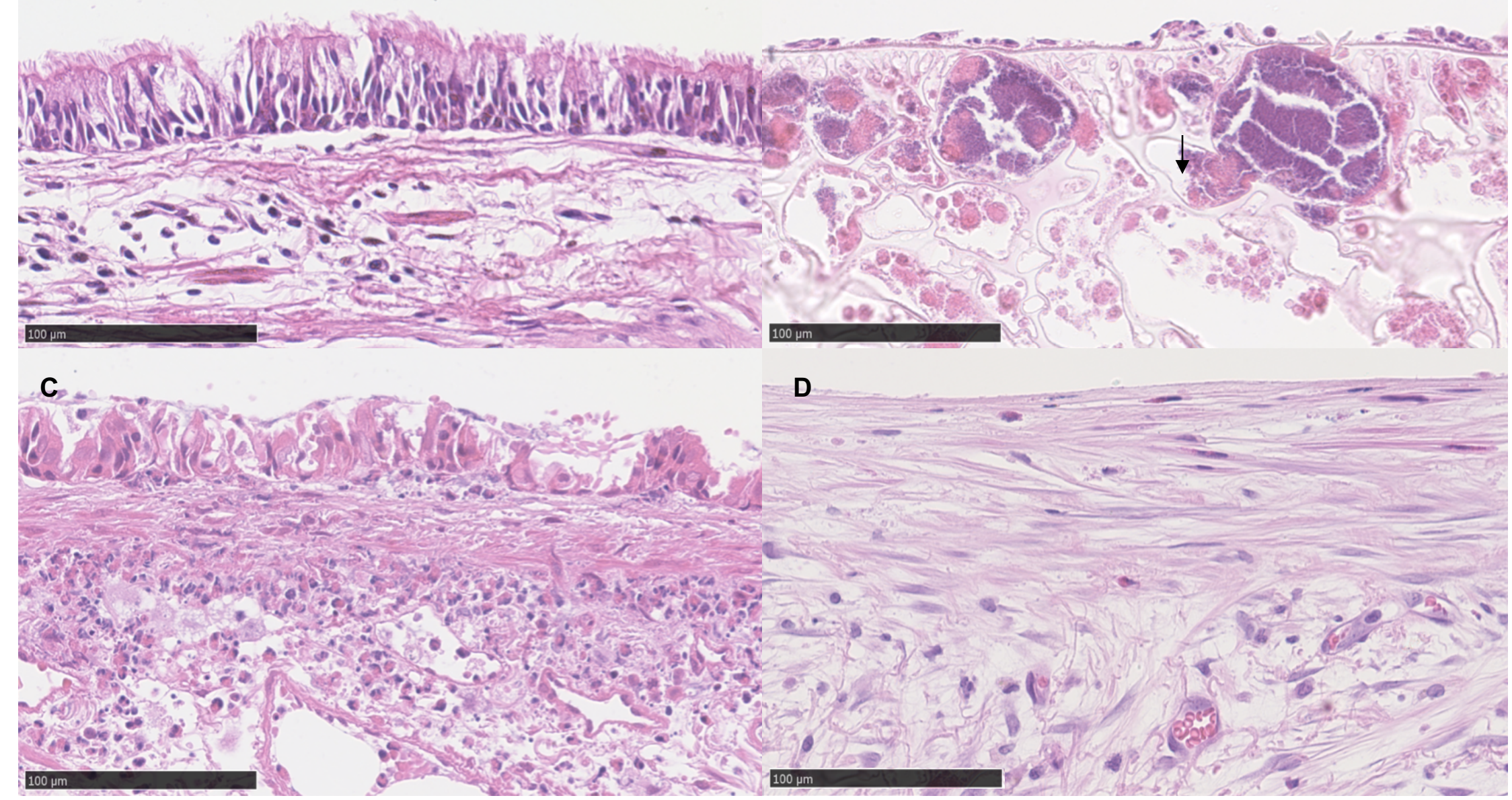

Figure 2: Haematoxylin \& Eosin stain of luminal surface at mid-point of graft - scale bar $100 \mu \mathrm{m}$.

(A) Control - largely intact layer of pseudostratified respiratory epithelium. (B) POSS-PCU - No respiratory epithelium seen, eosinophil migration throughout graft (arrow). (C) Herberhold - fixed donor epithelium seen with copious lymphocytic infiltrate. (D) Decellularized - Fibroblastic expansion of luminal surface without respiratory epithelium. 


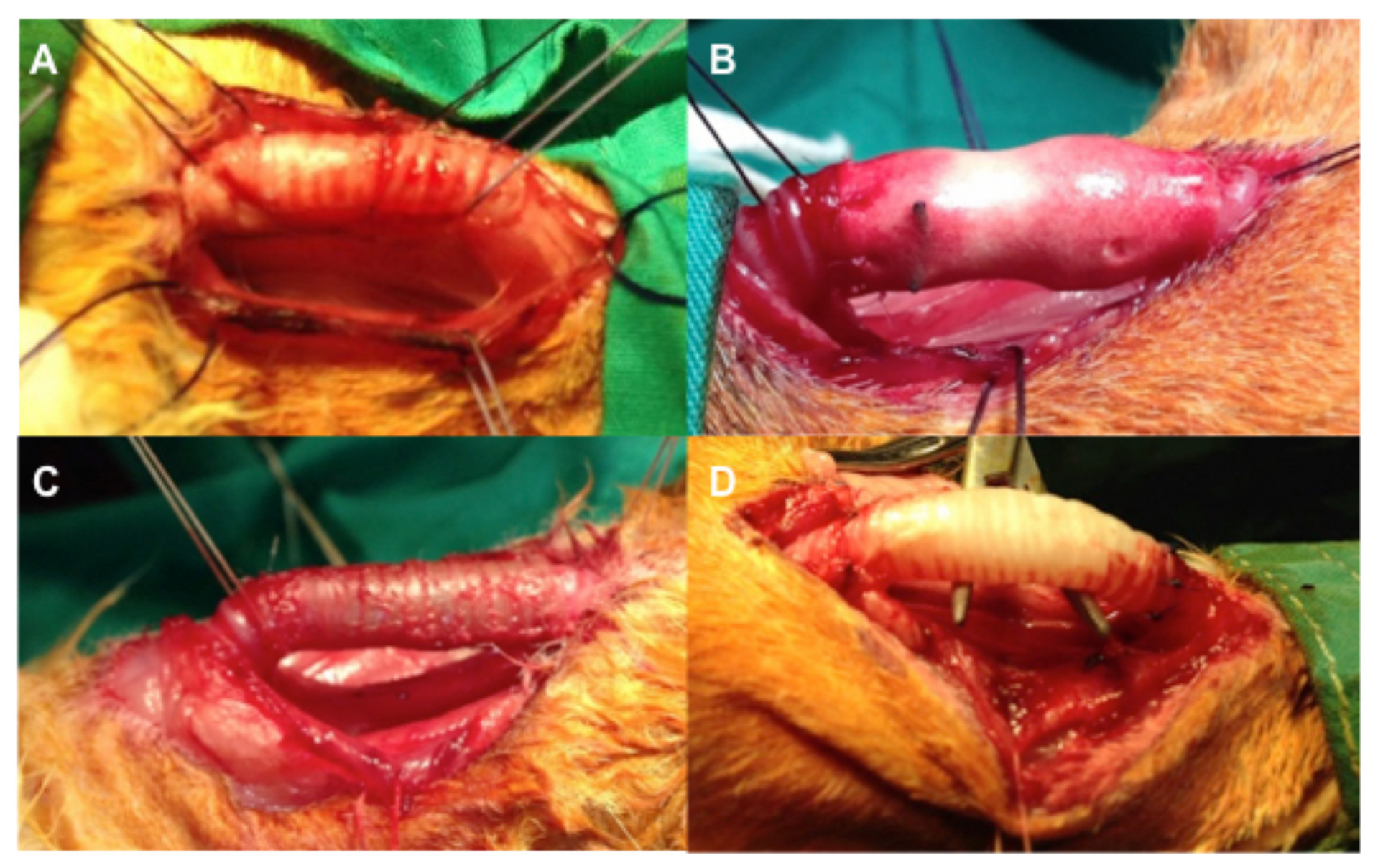

Supplementary Figure 1: Representative intraoperative photographs of end-to-end anastomosis of (A) control, (B) POSS-PCU, (C) Herberhold and (D) Decellularized grafts. 


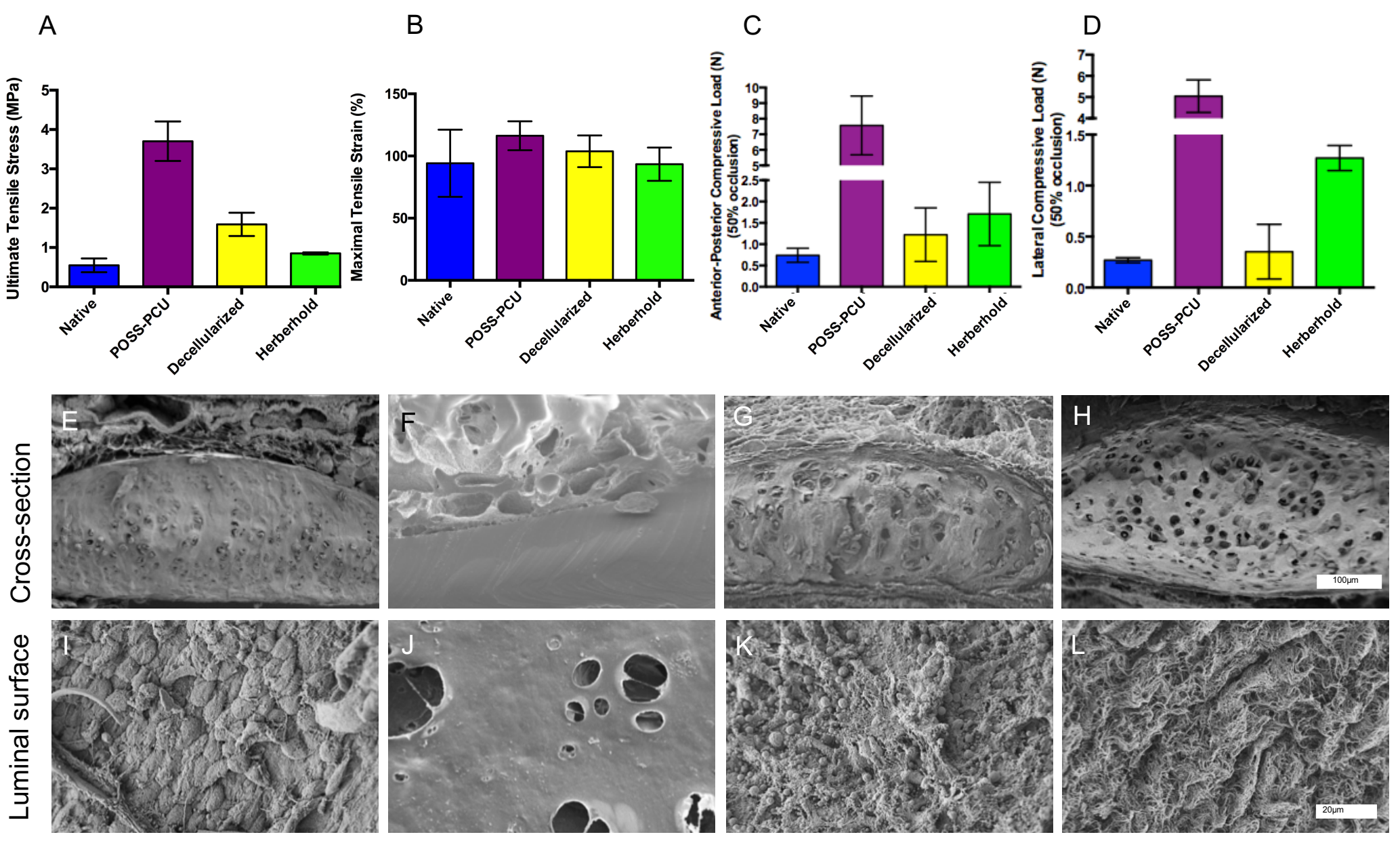

Supplementary Figure 2: Preimplantation analysis of grafts.

Biomechanical Testing: comparisons of ultimate tensile stress (A); ultimate tensile strain (B); anterior-posterior (C) and lateral (D) compressive load at $50 \%$ occlusion.

Scanning electron microscopy of scaffolds. Transverse sections x 200 magnification: (E) Control rabbit trachea; (F) POSS-PCU scaffold; (G) Herberhold and (H) Decellularized grafts. Luminal surfaces x 1000 magnification: (I) Control rabbit trachea; (J) POSS-PCU scaffold; (K) Herberhold and (L) Decellularized grafts. 


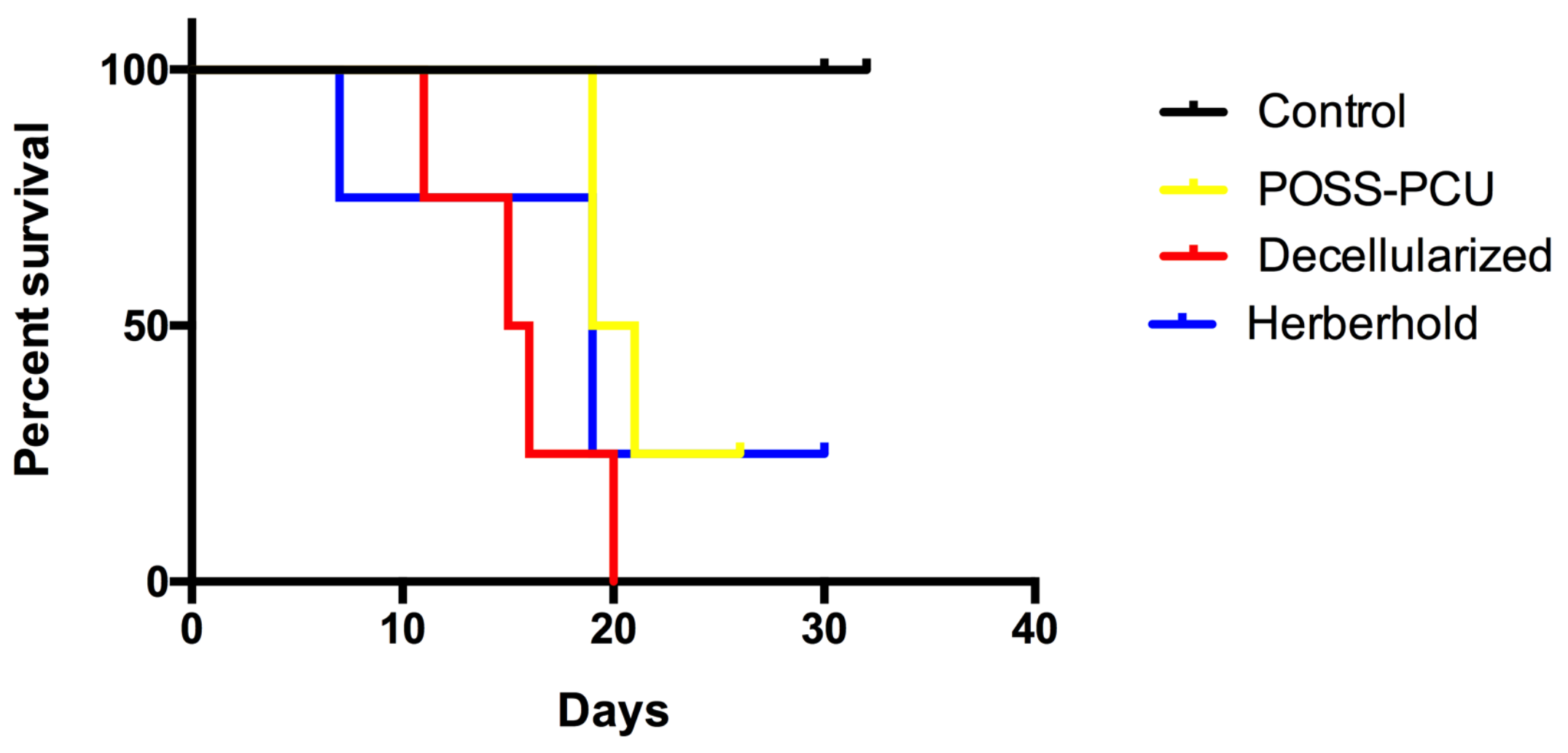

Supplementary Figure 3: Kaplan-Meier survival curves to experiment termination at 30 days. 


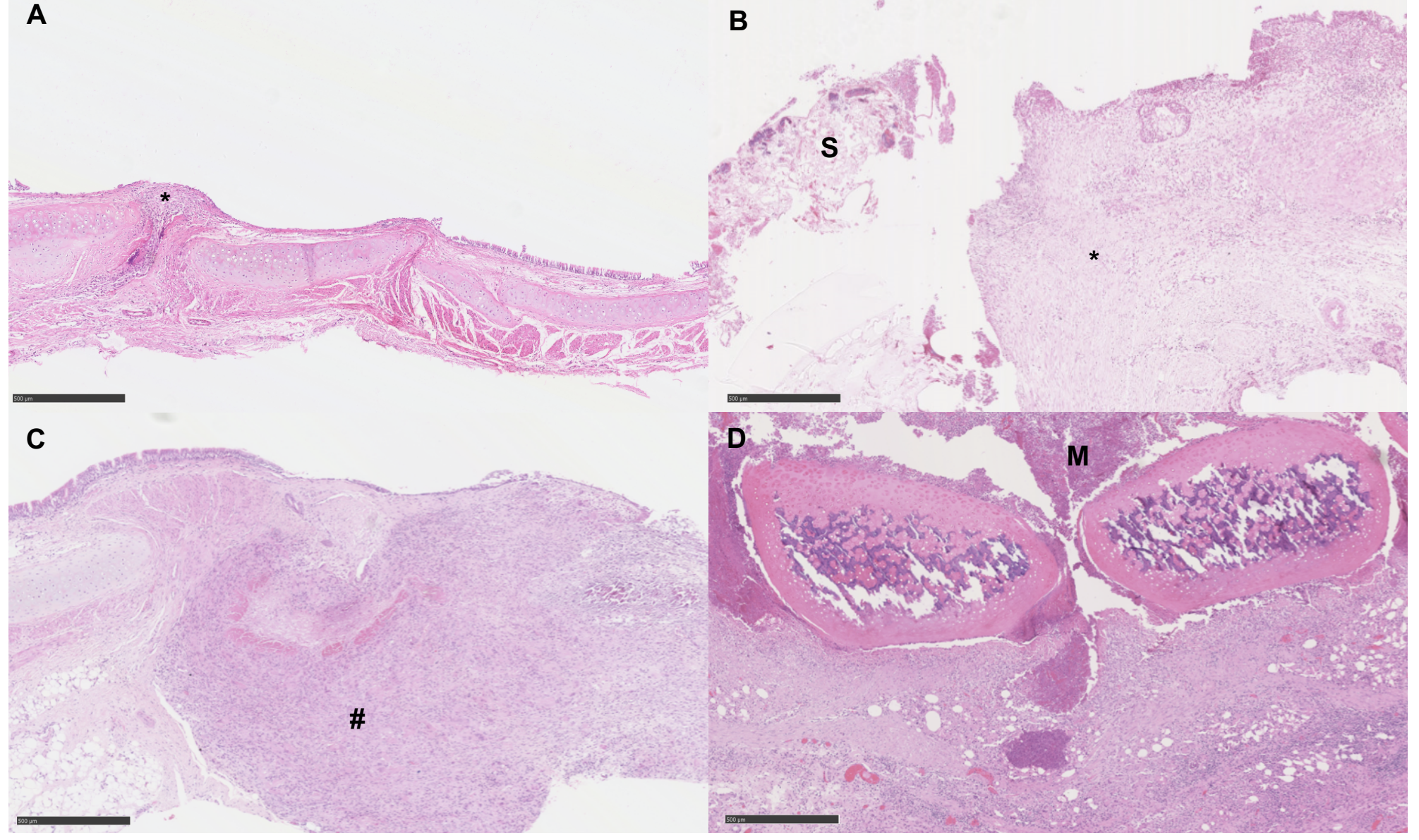

Supplementary Figure 4: Haematoxylin \& Eosin stain of longitudinal sections through anastomoses scale bar $500 \mu \mathrm{m}$.

(A) Control - minimal anastomotic granulation $\left({ }^{*}\right)$. (B) POSS-PCU - lack of scaffold (S) integration with florid overgrowth of granulation tissue $\left(^{*}\right)$. (C) Herberhold - florid anastomotic granulation tissue (G) with lymphocytic infiltrate (\#) throughout graft. (D) Decellularized - large submucosal expansion with fibroblastlike cells with mucus-filled lumen (M). 


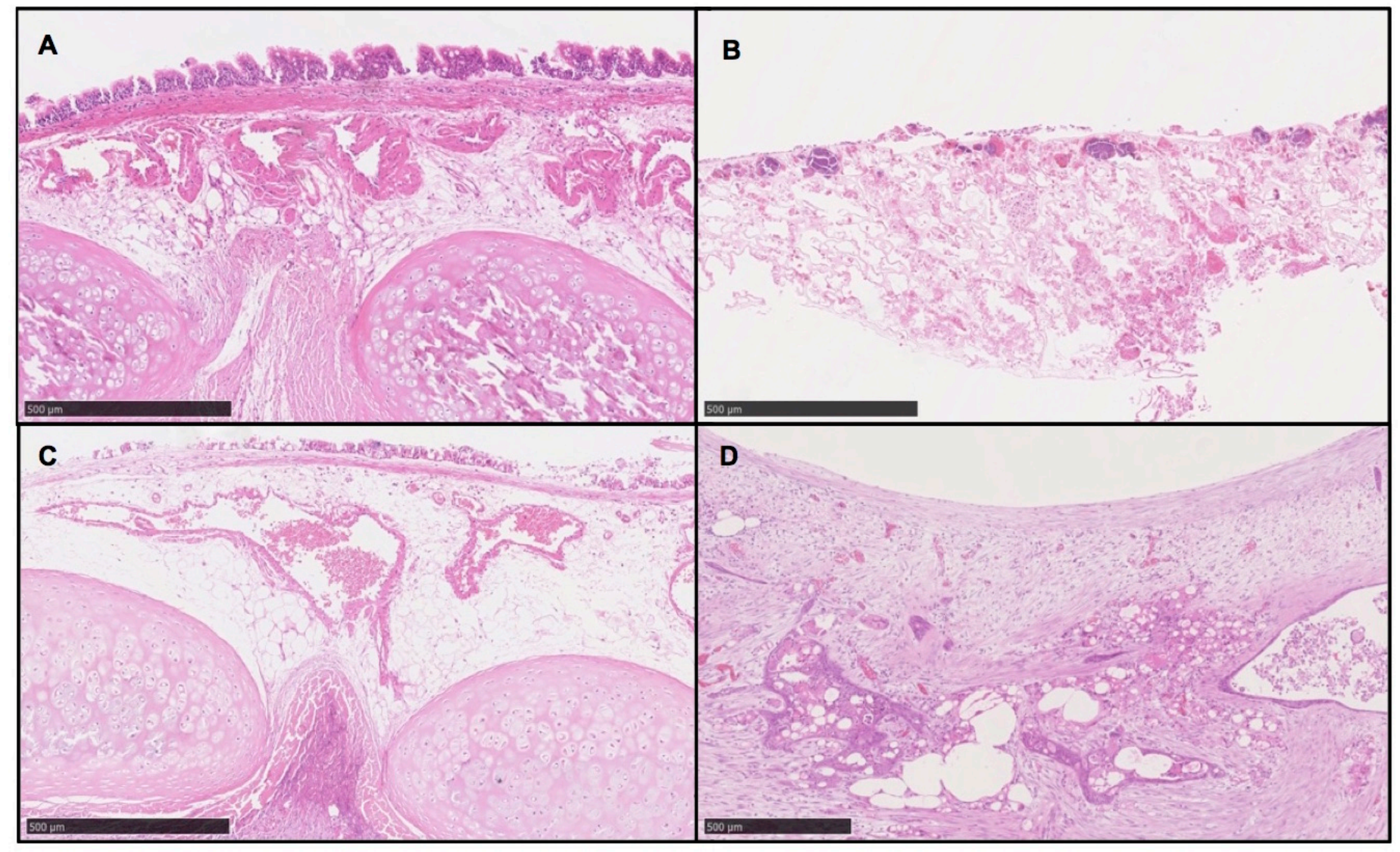

Supplementary Figure 5: Haematoxylin \& Eosin (H\&E) staining of submucosal layer at mid-point of graft. Scale bar $500 \mu \mathrm{m}$. (A) Control - intact submucosal vasculature. (B) POSS-PCU - pores containing copious cell debris but no discernable vessels. (C) Herberhold - intact submucosal vasculature with red blood cells within lumen. (D) Decellularized grafts - copious granulation tissue and irregular neovascularization with expansion of submucosal layer, suggesting in-stent stenosis. 
Supplementary Table 1: Adaptation of the Cotton-Myer grading system for subglottic stenosis

\begin{tabular}{|l|l|}
\hline Grade & Definition \\
\hline 0 & Ridging of airway wall only \\
\hline I (Mild) & $\begin{array}{l}\mathbf{0 - 5 0 \%} \text { stenosis } \\
\text { Stenosis visibly distorting luminal wall, but scope passable to carina. }\end{array}$ \\
\hline II (Moderate) & $\begin{array}{l}\mathbf{5 1 - 7 0 \%} \text { stenosis } \\
\text { Moderate stenosis, just unable to pass scope }\end{array}$ \\
\hline III (Severe) & $\begin{array}{l}\mathbf{7 1 - 9 9 \%} \text { stenosis } \\
\text { Severe stenosis visible }\end{array}$ \\
\hline IV (Very Severe) & 'Pinhole' stenosis/No lumen detectable \\
\hline
\end{tabular}

